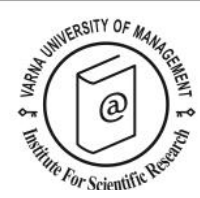

\title{
A motivation-based segmentation of Italian Airbnb users: an exploratory mixed method approach
}

\author{
Giacomo Del Chiappa ${ }^{1 *}$, Luca Sini ${ }^{2}$ and Marcello Atzeni ${ }^{3}$
}

\footnotetext{
${ }^{1}$ Department of Economics and Business, University of Sassari, Sardinia, Italy. Via Muroni, 25, o710o Sassari, Italy. Phone: +39 0789 6421 84, Senior Research Fellow, School of Tourism \& Hospitality, University of Johannesburg, South Africa. E-mail: gdelchiappa@uniss.it.

2 Department of Economics and Business, University of Sassari, Sardinia, Italy

3 Department of Economics and Business, University of Cagliari \& CRENoS, Sardinia, Italy

${ }^{*}$ Corresponding author
}

\begin{abstract}
Existing studies applying a motivation-based segmentation of Airbnb users are still limited and mainly concentrated in the US; even less are studies applied in the European context. This paper applies an exploratory mixed method approach in Italy, where no study has been published around this research area so far. A qualitative study based on 26 in-depth interviews was carried out to verify if Italians are driven by the same motivations that have been identified by existing literature. Qualitative findings were then used to inform, complemented with a review of the existing literature, to design a survey instrument to collect data. Hence, a factor-cluster analysis was run to profile a sample of 247 Italians based on their motivations to use Airbnb, and a series of chi-square tests was run to investigate whether significant differences exist among clusters based on socio-demographic characteristics (gender, age, marital status, level of education, employment status, and annual income). Three clusters were identified ("Enthusiastic Airbnb lovers", "Pragmatic Airbnb users" e "Pragmatic authenticity seekers") with significant differences only based on marital status, level of education and employment status. Contributions to the body of knowledge and managerial implications are discussed and suggestions for further research are given.
\end{abstract}

Keywords: Airbnb; motivations; socio-demographic characteristics; segmentation; mixed method, Italy

Citation: Del Chiappa, G., Sini, L. and Atzeni, M. (2020). A motivation-based segmentation of Italian Airbnb users: an exploratory mixed method approach. European Journal of Tourism Research 25, 2505.

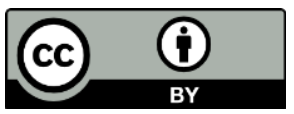




\section{Introduction}

In recent years, the advent of the sharing economy has emerged as a major destructive trend completely re-shaping the global tourism and hospitality industry (Aznar, Maspera and Quer, 2019; Dudás et al., 2019; Hsu et al., 2016). In such a scenario, "touristic consumers have resources and can organize among themselves or mingle with the closely related residential consumer species and act like producers" (Gretzel et al., 2015, p. 561). This has given rise to the so-called sharing economy phenomenon.

The topic of sharing economy (SE) has significantly attracted the attention of researchers and practitioners (Dolnicar, 2018). When analysing the concept of sharing economy from a consumerbehaviour perspective, researchers tend to use the term "Collaborative Consumption (CC)" (Albinsson and Perera, 2012; Belk, 2014). This term usually refers to "a peer-to-peer-based activity of obtaining, giving, or sharing the access to goods and services, coordinated through community-based online services" (Hamari, Sjoklint, and Ukkonen, 2016, p. 2047). In general, different types of peer-to-peer accommodation platform can be acknowledged based on their business model. In such context, offering completely free of charge hospitality experiences (e.g. CouchSurfing) represents one end of a continuum, whereas other platforms exist representing more of a commercial exchange between host and guest; Airbnb can be positioned in the middle of this continuum (Reinhold and Dolnicar, 2017). Peer-to-peer accommodation platforms can be also categorised as free (e.g. CouchSurfing), reciprocal (e.g. HomeExchange) and rentals (e.g. Airbnb, gflats) (Palgan, Zvolska and Mont, 2017).

In 2018, the share of $\mathrm{P}_{2} \mathrm{P}$ accommodation accounted for about $7 \%$ of the global accommodation supply (Bakker et al., 2018). Airbnb has experienced a relevant growth in the EU and US reaching a market penetration of approximately 25\% (Volgger, Taplin and Pforr, 2019). By January 2019, 500 million guests had used Airbnb choosing among more than six million listings available in more than 100.00o cities worldwide (Airbnb, 2019). According to Bakker et al. (2018), the expected annual growth rate for the $\mathrm{P}_{2} \mathrm{P}$ accommodation economy is expected to be 31\% between 2013 and 2025. In April 2017, 214,483 accommodations were listed in Airbnb in Italy (Federalberghi, 2017), thus registering an increase of $28,59 \%$ when compared to 2015, when the total number of listings was 177,865 (Federalberghi, 2016). On the whole, in 2017, Airbnb generated 30.3 million of overnights stay in Italy, out of a total of 111.4 million (Federalberghi, 2017).

SE platforms, and accommodation facilities listed in there, have become among the most relevant competitors for hotels (Freitag and Haywood, 2015), able to have an impact over their prices, sales and occupancy rate (e.g. Aznar, Maspera and Quer, 2019; Dudás et al., 2019). The growing interest that travellers seem to express toward the possibility to replace standardised tourist experiences with experiences that allow them to be in touch with the local community, the local identity and authenticity (Decrop et al., 2018), makes it urgent to consider these renewed tourists' habits or tastes in any hospitality business, with the accommodation sector certainly not being an exception. Hence, in the current competitive scenario, traditional hospitality providers should consider the emerging need of "sharing" expressed by travellers in developing their marketing strategy. Understanding such trends would enable them to transform a potential threat into an opportunity to implement new business models. The challenge is to find a way to facilitate the exchange and the sharing practices among users that interact with the provider itself and with each other (Corciolani, 2015).

Academic research regarding the SE has been growing in the last decade and a growing attention has been devoted to the analysis of the motivations that drive consumers to use sharing economy platforms such as Airbnb (Reinhold and Dolnicar, 2017). In this vein previous studies referred to the 
sense of community (Guttentag et al., 2018), authenticity (Lamb, 2011) or familiarity and trust (Möhlmann, 2015) as being among the main motivational factors. Recent research also highlighted the importance of more materialistic and individualistic motivations, such as economic and home benefits (Guttentag et al., 2018; Möhlmann, 2015; Nowak, 2015; Tussyadiah, 2015; Tussyadiah, 2016).

However, there is limited research devoted to analyse behaviour and profiles of Airbnb (Volgger, Taplin and Pforr, 2019). Particularly, there is still a handful of academic studies devoted to the analysis of motivations driving consumers to use Airbnb, with the most part of existing papers being devoted to specific geographical area and countries (e.g. USA, Canada, Australia, etc.), and rarely adopting a segmentation-based approach (Guttentag et al., 2018). Hence, there is still a need to deepen the scientific debate about what drives consumers to use Airbnb, especially in those European countries that generate relevant tourism flows and/or show significant cultural differences when compared to those where studies have already been conducted. This study was therefore carried out in Italy with the specific aim of contributing to academic literature devoted to analyse motivations driving consumer to use Airbnb. Several reasons contribute to explain why Italy was selected as the research setting for this study. First, in the best of our knowledge there has been no published academic paper devoting to profile Italians based on their motivations to use Airbnb, thus this research contributes to expand the geographical understanding of the Airbnb phenomenon in a relevant source market for many countries worldwide, especially in Europe. Secondly, Italy is the third most important country within the Airbnb platform when considering the number of listings posted online (Airbnb, 2016). Furthermore, Italy shows relevant cultural differences when compared to countries that have been investigated in current research (Hofstede, 2017). All the aforementioned considerations render the Italian context a suitable country to carried out this study. In particular, this research applied an exploratory mixed method approach. Specifically, a qualitative study based on 26 in-depth interviews was carried out with Italians to deepen our understanding about the main motivations driving them to use Airbnb platform (study 1). This was done to verify if Italians are driven by the same motivations that existing studies have used to dig on tourist behaviour in different countries and/or whether different motivations should be taken into consideration. Qualitative findings were then used to inform, complemented with a review of the existing literature, to design a survey instrument that was adopted to collect data from a sample of 247 Italians (study 2). Hence, a factor-cluster analysis was run to profile the sample based on motivations to use Airbnb, and a series of chi-square tests was run to investigate whether significant differences exist among clusters based on socio-demographic characteristics (gender, age, marital status, level of education, employment status, and annual income).

\section{Literature review}

According to Crompton (1979, p. 409-410) motivation "is considered a critical variable because it is impelling and compelling force behind all behaviours"; in other words, motivation represents the basis of any kind of human behaviour, including travelling, thus explaining why the analysis of motivations driving consumer behaviour has been attracting huge attention from both researchers and practitioners (Seabra et al., 2016).

In recent years, swapping, bartering, sharing and short-term renting have become alternative forms for consumers to access and to consume goods and services in any sector, and tourism and hospitality are certainly not an exception. Labelled as the sharing economy for some (e.g., Lessig, 20o8), collaborative consumption for others (e.g., Botsman and Rogers, 2010), these alternative consumption practices have attracted the interest of both researchers and practitioners and several studies have 
been developed to investigate the motivations driving consumers to use these platforms (Hardy and Dolnicar, 2018).

For example, Balck and Cracau (2015) analysed motivations to use SE platforms in several sectors, named: accommodation renting, car sharing, commodities and clothing. Based on their analysis, the authors identified five key drivers: "cost"; "rarity"; "environment"; "access"; "no ownership". Further than for doing something good or useful for other peers and for the environment (Prothero et al., 2011), CC platform can be also used for more materialistic and individualistic benefits, such as saving money or simplifying access to resources. In this vein, Hamari et al. (2016) further argued that people use such platforms driven by the following motivations: seek for enjoyment, contribution to sustainability, to gain economic benefits, for reputation-based considerations. Other studies confirmed that consumers participate in CC mainly for extrinsic reward such as convenience or cost savings (e.g. Guttentag et al., 2018). Similarly, based on Benoita (2017) and Sthapit et al. (2019), consumers use $\mathrm{CC}$ to gain economic benefits, as a way to gain social and hedonic value and to reduce risks.

Giving attention to the studies devoted to the analysis of motivations to use sharing economy platform in the field of tourist services, a relevant number of studies has been devoted to the analysis of $\mathrm{P}_{2} \mathrm{P}$ application in the context of the accommodation sector such as CouchSurfing (Decrop et al., 2018) or Airbnb (e.g. Guttentag et al., 2018). Möhlmann (2015) in her study on car2go (car sharing) and Airbnb (accommodation sharing) found that the main motivation to use sharing economy platform are: cost savings, trust, familiarity, and utility. Similarly, Tussyadiah (2015) investigated the Airbnb community and differentiated between motivations to use (i.e. sustainability, community and economic benefits) and not to use this platform (e.g. lack of trust and efficacy). Based on current studies, environmental and sustainability-based motivation appear to be the least important in driving consumers to use Airbnb (Barnes and Mattsson, 2016).

To sum up, the main motivations driving consumers to use Airbnb are as follows (Botsman and Rogers, 2010; Guttentag, 2015; Möhlmann, 2015; Tussyadiah, 2016):

$\checkmark$ to save costs and achieve economic benefits, one of the most important motivation in all the existing studies devoted to the Airbnb setting (Guttentag et al., 2018; Möhlmann, 2015; Nowak, 2015; Tussyadiah, 2015);

$\checkmark$ to take advantage of services and add-on benefits that are more "home based" (the so called "home benefits": space, furniture, etc.) (e.g. Quinby, 2014; Tussyadiah, 2016; Tussyadiah and Zach, 2017);

$\checkmark$ to find room availability in geographical areas that are not served by more traditional accommodations services and/or that are crowded and fully booked during the peak of the tourism season (Guttentag et al., 2018; Nowak, 2015; Tussyadiah and Zach, 2017);

$\checkmark$ to take advantage of ease of communication, responsiveness, flexibility of the check-in and check-out time (Möhlmann, 2015; Tussyadiah, 2016).

$\checkmark$ to interact with the hosts and the local community and to receive useful tips about how to experience the place (the so-called "sense of community and interaction": e.g. Guttentag et al., 2018).

$\checkmark$ to enjoy an authentic local experience and/or to be hosted in a non-touristic area (Authenticity: e.g. Lamb, 2011; Nowak et al., 2015);

$\checkmark$ to spend money to favour the economic health of locals and to use environmental friendly accommodation (the so called "sharing economy ethos": Guttentag et al., 2018); 
$\checkmark$ to experience something that they perceived to be much more familiar and more trustworthy (the so called: "familiarity and trust": e.g. Möhlmann, 2015);

$\checkmark$ to feel a genuine and warm sense of welcoming and hospitality (the so-called "feeling home": e.g. Tussyadiah, 2016).

$\checkmark$ to experience something unusual or non-standardised (the so called "novelty": e.g. Guttentag et al., 2018);

Marketing theory agrees that market segmentation is critical in terms of effectiveness and efficiency and concurs that different variables/approaches can be used, even combining them, to profile consumers (e.g. benefit, motivations, sociodemographic, psychographic and behavioural characteristics, etc.) (Kotler, 1980). Currently, a reasonable number of academic papers exist applying segmentation in the growing research area related to peer-to-peer applications and user generated content.

Motivations have been also used to profile consumers who used Airbnb. For example, Guttentag et al. (2018) recently offered a motivation-based segmentation analysis applied to a sample of US, Canadian and European consumers and identified five consumers clusters: Money Savers (young users who are mainly attracted by Airbnb's lower prices when compared to those of traditional hospitality providers); Home Seekers (older and with a higher level of education, who are appealed by the home benefits offered by the accommodation providers in Airbnb); Collaborative Consumers (international travellers and backpackers who frequently use Airbnb); Pragmatic Novelty Seekers (young consumers particularly sensitive to the novelty of the listings and to the availability of home benefits); Interactive Novelty Seekers (mainly backpackers who book shared accommodations attracted by the novelty of the offer and by the opportunity to interact and socialise). The study also showed that significant differences exist among clusters based on certain socio-demographic characteristics (e.g. age and education) whilst others were not significant (e.g. gender and household income). Further than this study, it could be argued that academic studies devoted to profile consumers based on their motivation to use Airbnb are still limited and/or have been barely applied to European countries, where no academic paper exist so far aimed at applying a motivation-based segmentation to Italian consumers. This occurs despite the fact that Italy is a relevant source market for several European and non-European countries and also for domestic tourism. Further, Italy would be an interesting context to be investigated given the relevant cultural differences with others geographical area that have been already investigated.

Existing literature considers culture as a relevant factor in the field of consumer behaviour in any sector, and tourism is certainly not an exception (e.g. Pizam and Sussmann, 1995; Forgas-Coll et al., 2012). For example, based on Torres et al. (2014), individuals with different cultural backgrounds assess the same experience differently and adopting different points of view. Torres et al. (2014) showed that guests from different cultures can also be delighted by different services and amenities. Hofstede (1993) proposed five dimensions to identify cultural differences and to investigate crosscultural consumer behavior, namely: power distance, individualism/collectivism, masculinity/ femininity, uncertainty avoidance, and long/short-term orientation.

In this scenario, Italy appears to be an interesting context to be investigated, given the relevant cultural differences with other geographical areas that have been already investigated, to deepen the scientific debate around the motivations driving consumer to use Airbnb. For example, when compared to Canada and US (Guttentag et al., 2018), Italy differs in three out of the six dimensions considered by Hofstede (2017). Specifically, Italians register a high "Uncertainty avoidance" score (76) in comparison to USA (36) and Canada (38), meaning that Italians are not comfortable in ambiguous situations, as the switch from traditional businesses to $\mathrm{P}_{2} \mathrm{P}$ services could be perceived; furthermore, 
the fact that Italy has a high uncertainty-avoiding culture suggests that Italians are expected to have a lower novelty-seeking tendency when compared to low uncertainty-avoidance cultures (Blas and Carvajal-Trujillo, 2014). Second, Italy shows a higher score in "Long term orientation" (61) when compared to Canada (36) and USA (26); this could be explained by arguing that Italians tend to be pragmatic people with the ability to easily adapt themselves to renewed conditions. Third, Italy shows a lower score in term of "Indulgence" (30) when compared to USA (68) and Canada (68), meaning that Italian culture is "restraint" with tendency to pessimism and limited emphasis on leisure time and gratification. Finally, Italy scores lower in term of "Individualism" (71) when compared to Canada (80) and United States (91), meaning that Italians, in their choice to use Airbnb, should be driven more by altruistic reasons (e.g. make reservations to pay money that go to locals or to help to protect the environment) when compared to more individualistic countries. The aforementioned arguments render Italy a perfect research setting where to apply studies aimed to answer to recent calls for further research applying motivation-based segmentation study of Airbnb users (Guttentag et al., 2018). For the purposes of this research a double-stage methodology (i.e. exploratory mixed-method approach: Teddlie and Tashakkori, 2009) was adopted. Specifically, a first qualitative study with indepth interviews was carried out to verify whether different motivations could emerge from interviewing consumers living in a country (i.e. Italy) that shows cultural differences when compared to countries where existing studies have been conducted so far. Hence, the output of this first qualitative study, complemented with a review of the existing literature, was used to design the questionnaire to be used in a second quantitative study.

\section{Methodology}

For the purposes of the study, an exploratory sequential design was chosen as a methodology in which qualitative research acts as groundwork for a quantitative study (Creswell \& Plano Clark, 2017).

The interview protocol used for the qualitative study included two parts. The first aimed at collecting some information about key socio-demographic characteristics of respondents. The second, included some open-ended questions aimed at investigating the main motivations driving consumers to use Airbnb. Respondents were selected among those who had used Airbnb to make a reservation in the last twelve months prior to the interviews.

Data saturation was achieved through 26 interviews due to the final similarity in responses given by the participants (Patton, 2002). Interviews were conducted in the period April-June 2017. On the whole, the interviews lasted between 20 and 40 minutes, were digitally recorded and then transcribed by the research team. Italy was the location where interviews were conducted. The interviews were transcribed and then translated to English, as they were conducted in Italian. Hence, the researchers read the transcripts to familiarise with the narratives and to clarify any issues arising from the translation (e.g. Suh et al., 2009).

The data were then analysed through thematic coding to identify motivations to use Airbnb to book accommodation services, with both open and axial coding. The initial codes were reviewed by the research team, an independent researcher not involved in the study was brought in to revise the coding and to decide whether he/she agreed with the codes. Whenever the research team and the independent reviewer disagreed about the coding, discussions were made until an agreement was reached. Hence, the final coding was undertaken, and the identified themes were matched with existing studies. 
The output of the first qualitative study, complemented with a review of the existing literature (e.g. Guttentag et al., 2018), was used to design the questionnaire to be used in a second quantitative study. An online survey, using a snowball sampling technique, was considered the best choice to collect the data. In fact, it is frequently used when researchers are in a need to cope with financial constraints in managing the research project and when subjects of the desired population are difficult to be identified, located and accessed (Wrenn et al., 2007).

The initial sample were generated from 1,00o contacts provided by an Italian tourism association based in the centre of Italy. These individuals received an email inviting them to complete the online survey by clicking on a link provided in the e-mail and were encouraged to forward the survey to their friends and acquaintances. Further, the link to the online survey was also posted on social networks.

The online survey invited potential participants to answer a qualifying question: "Have you ever used Airbnb to reserve an accommodation in the last 12 months?". Only those respondents providing a positive answer were considered for the purpose of this paper. The survey instrument was divided in two parts. The first one asked respondents to assess their level of agreement with a list of 22 items specifically used to investigate their motivations to use Airbnb; a 5-point Likert scale (1=I completely disagree, 5= I completely agree) was used for measure their answers. The second section asked respondents to provide some general socio demographic information (i.e. age, gender, level of education, marital status, employment status and annual household income).

After a three-week period (during June 2017), a total of 501 respondents were reached, of which 241 surveys were from users of Airbnb and 254 from non-users.

\section{Results}

The following subsections present and discuss the results pertaining the qualitative and quantitative study.

Results of the qualitative study

Overall, 26 respondents were involved in the qualitative stage of our research (see table 1 in the appendix). Specifically, 14 were females and 12 were males. The average age of the participants was of 38,7 years old, with the youngest interviewee aged 26 and the oldest aged 61. Most respondents were reported to be highly educated and employed; all of them reported having independently planned/booked their stay online.

On the whole, our qualitative findings largely confirm the motivation to use Airbnb as identified by existing studies, and as reviewed and summarized in the motivation-based segmentation study published by Guttentag et al., (2018) (see table 2). Specifically, they suggest that Italians tend to use Airbnb for getting economic benefits, interaction, novelty, home benefits and economy pathos. At the same time, our findings suggest that new motivations should be taken into account when analysing why Italians use Airbnb to reserve accommodation facilities for their holiday. 
Table 2. Motivations to use Airbnb

\begin{tabular}{lll}
\hline Factor/Motivation & Quote & ID \\
\hline $\begin{array}{l}\text { Convenience/economic benefits } \\
\text { For the convenient location* }\end{array}$ & $\begin{array}{l}\text { "I decided to use it because the location was really convenient } \\
\text { as it was in an area without hotel availability" }\end{array}$ & SE03 \\
For its comparatively low cost* & "... I like the fact that I can save a lot of money." & SEo6 \\
\hline
\end{tabular}

Interaction

To receive useful local info/tips from my host*

"...you can ask the hosts to provide tips about what is

available, or what to do and what to see at destination...they

offer you tailor-made and personalised information even before reaching the destination..."

To interact directly with host, locals* "I love it because there is no intermediary...I can contact the host directly and manage everything with him/her."

\section{Home benefits}

For the homely feel*

For the large amount of space*

For the access to household amenities* $^{*}$
“...I use Airbnb because I want to experience the destination differently...not in a hotel but in an apartment so that I can have the opportunity to feel like being at home..."

“...I prefer to use Airbnb because you can have more space at your disposal and to be shared with your travel companions"

"...you can find a lot of independent housing with all the necessary amenities that you might not find in any hotel”
SE14

SE15

SE19

\section{Novelty}

I think the experience would be exciting*

To do something new and different*

To have experience I could tell friends/family about*

"...When you use Airbnb you often gain the possibility to have an exciting experience...I mean you can have a great interaction with the hosts, usually they are very kind, they give a lot of information about that area, they let you have wonderful local experiences..."

"...To stay in a local style-oriented apartment and to experience something that it is really different from a type of accommodation I could find for example in Booking.com..."

"...the most memorable experience I have is when I used Airbnb to stay in Japan...I was treated as a "king", I received a hospitality that I could never experience in any other place...the host picked me up when I arrived in the city, he let me try a typical breakfast and offered me a bottle of local wine... he provided me a lot of advice...that was an experience I always tell and suggest to my friends..." 
I think the experience would be unpredictable ${ }^{*}$

To have a unique (non-standardised) experience*
“...Once I booked on Airbnb...I should have had a private room SE16 for my own, but then I realised I would have shared it with the owner (a girl) in an open space divided in two by a "fake wall". I never had a sharing experience before... After two days we became friends... At the beginning it was a peculiar situation but in the end I really enjoyed it, it was unpredictable but finally I think I was lucky...that is something I hope it might happen again when I use Airbnb..."

"I use Airbnb to live a unique experience that is really different from the standardised one you can usually experience when staying in a hotel"

\section{Sharing economy pathos}

I want the money I spend to go to locals*

Staying with Airbnb is environmentally friendly*

I prefer the philosophy of Airbnb*
“...I use Airbnb because I I got the idea that in this way my money will go to the host who is a resident..."

"The perception I have about Airbnb-related accommodations is that they consume less energy and are more environmentally friendly..."

"I prefer to use Airbnb because it reflects my way of being and of travelling, it is a bit more human and personally-driven...I feel like they are taking care of me"
SE14

SE21

SE21

$\mathrm{SE} 22$

\section{Local authenticity \\ To have an authentic local experience* \\ To stay in a non-touristy neighbourhood*}

"An Airbnb consumer is an individual who travels in search of authentic experiences rather than in search of a standardised journey....I'm an Airbnb type of traveller"

"Airbnb is probably the best way to get in touch with other people... and to get along with the local people even in not touristy neighbourhoods"

\section{Emotional pathos}

To live a pleasant experience ${ }^{* *}$

To live a stimulating experience ${ }^{* *}$ experience by dealing with local people and people like me...” "Airbnb is cooler... when I went to Japan it was really a
stimulating experience because I had the chance to stay in a traditional Japanese house..."

To live a fun experience** "To me, using Airbnb means to have much more fun by being in contact with people...this is what I like the most"

"When you travel traditionally you tend to visit the classic touristic and most known attractions... you might lose the

To live an interesting experience ${ }^{* *}$ possibility to experience the most interesting and hidden things...with Airbnb you can end up doing something that is much more interesting (SEog)

To live an enjoyable experience** "You can live an enjoyable experience when using Airbnb..."

\footnotetext{
* confirmed in Guttentag et al. (2018), ** identified based on our interviewees
} 
In particular, they suggest that Italians are driven to use Airbnb platform by thinking that it can offer them the possibility to live a pleasant, stimulating, fun, interesting and enjoyable experience (e.g. emotional-based pathos), thus further underlying and stressing the experiential-based nature that Airbnb has for this target market.

Results of quantitative study

Table 3 shows the socio-demographic characteristics of respondents. Most of them were female $(65.0 \%)$, aged mostly $21-30$ (32.1\%) or 31-40 (35.8\%), married or cohabiting (50.0\%), with a bachelor's degree (47.3\%) and administrative workers (35.0\%).

Overall, Italians appear to be motivated to use Airbnb mainly for functional factors such as: economic benefits (e.g. "For its comparatively low cost": $M=4.27$, "For the convenient location": $M=3.32$ ), home benefits (e.g. "For the access to household amenities": M=3.57, "For the large amount of space": $M=3.39$ ). The second main group of motivations is represented by more emotional-based experiential drivers; in fact, respondents scored relatively high on items such "To live an enjoyable experience" $(\mathrm{M}=3.53)$, "To live an interesting experience" $(\mathrm{M}=3.34)$ and "To live a nice and pleasant experience" $(\mathrm{M}=3.33)$. On the contrary, authenticity-based and sustainability-based motivations were found to be the least important with respondents scoring low, or relatively low, on items such as "To interact with hosts and locals" (M=2.96), "I wanted the money I spent to go to locals" $(M=2,79)$ and "Staying with Airbnb is environmentally friendly" $(\mathrm{M}=\mathbf{2 . 4 3})$.

Table 3. Sociodemographic profile of the sample

\begin{tabular}{llll}
\hline Variables & \% & Variables & $\%$ \\
\hline Gender & & Employment & \\
Male & 35.0 & Executive manager & 4.6 \\
Female & 65.0 & Administrative worker & 35.0 \\
Age & & Freelance & 17.9 \\
16-20 & 2.5 & Retired & 0.8 \\
21-30 & 32.1 & Teacher & 7.9 \\
31-40 & 35.8 & Student & 20.0 \\
$41-50$ & 22.1 & Unemployed & 5.0 \\
$51-60$ & 5.8 & Other & 8.8 \\
$>61$ & 1.7 & Education & \\
Marital status & & Primary school & - \\
Single & 22.1 & Middle school & - \\
Married/cohabiting & 50.0 & High degree & 25.3 \\
Divorced & 0.8 & Bachelor's degree & 47.3 \\
Engaged & 26.3 & Master's degree/PhD & 26.1 \\
Widow/widower & 0.8 & Other & 1.3 \\
\hline
\end{tabular}

An exploratory factor analysis (EFA) was used to reveal the underlying factors in the data. This procedure allowed us to identify five factors explaining the $70.62 \%$ of total variance (Table 4 ). The KMO-index (Kaiser-Myer-Olkin = 0.907) and the Bartlett's test of sphericity (chi-square $=3,839.873$, p-value <0.00o1) confirm that the results are appropriate to explain the data. Cronbach's alpha was then calculated to test the reliability of the extracted factors; all values but one (convenience) are 0.7 or higher. Given that "convenience" showed a very low Cronbach's alpha it was not retained for the purposes of this study. The interpretation of the latent factors was done referring to the rotated factor matrix showing factor loadings for each factor, after the application of an orthogonal rotation 
(Varimax) which facilitates the interpretation without any further loss of information (Hair et al., 2014).

Table 4. Factor's names extracted using the principal components method

\begin{tabular}{|c|c|c|c|c|c|}
\hline & $\begin{array}{l}\text { Factor } \\
\text { Loading }\end{array}$ & $\begin{array}{l}\text { Eigen } \\
\text { value }\end{array}$ & $\begin{array}{l}\text { Variance } \\
\text { explained } \\
(\%) \\
\end{array}$ & $\begin{array}{l}\text { Cumulated } \\
\text { variance } \\
(\%) \\
\end{array}$ & $\begin{array}{l}\text { Cronbach } \\
\text { Alpha }\end{array}$ \\
\hline F1: Emotional-based pathos & & $9 \cdot 593$ & 43.61 & 43.61 & 0.952 \\
\hline To live an enjoyable experience & 0.796 & & & & \\
\hline To live a stimulating experience & 0.766 & & & & \\
\hline To live a fun experience & 0.823 & & & & \\
\hline To live an interesting experience & 0.818 & & & & \\
\hline To live a pleasant experience & 0.838 & & & & \\
\hline F2: Authenticity and sustainability & & $1.75^{2}$ & 7.96 & 51.57 & 0.876 \\
\hline To interact with host, locals & 0.691 & & & & \\
\hline To receive useful local info/tips from my host & 0.72 & & & & \\
\hline For the homely feel & 0.547 & & & & \\
\hline Wanted the money I spent to go to locals & 0.629 & & & & \\
\hline $\begin{array}{l}\text { Staying with Airbnb is environmentally } \\
\text { friendly }\end{array}$ & 0.582 & & & & \\
\hline I prefer the philosophy of Airbnb & 0.578 & & & & \\
\hline To have an authentic local experience & 0.719 & & & & \\
\hline To stay in a non-touristic neighbourhood & 0.598 & & & & \\
\hline F3: Novelty & & 1,52 & 6.91 & 58.48 & 0.887 \\
\hline For simple curiosity & 0.504 & & & & \\
\hline $\begin{array}{l}\text { I thought the experience would be } \\
\text { exciting and unique }\end{array}$ & 0.823 & & & & \\
\hline To do something new and different & 0.806 & & & & \\
\hline $\begin{array}{l}\text { To have experience I could tell friends/family } \\
\text { about }\end{array}$ & 0.754 & & & & \\
\hline $\begin{array}{l}\text { I thought the experience would be } \\
\text { unpredictable }\end{array}$ & 0.83 & & & & \\
\hline F4: Home benefits & & 1.406 & 6.39 & 64.87 & 0.735 \\
\hline For the large amount of space & 0.829 & & & & \\
\hline For the access to household amenities & 0.821 & & & & \\
\hline F5: Convenience & & 1.26 & 5.75 & 70.62 & 0.321 \\
\hline For its comparatively low cost & 0.585 & & & & \\
\hline For the convenient location & 0.714 & & & & \\
\hline
\end{tabular}

"Emotional-based pathos" summarises the $43.61 \%$ of total variance and is strongly correlated with items describing the feelings and emotions (e.g. fun, pleasant, etc.) that travellers think can obtain from their tourist experience when booking an accommodation through Airbnb.

"Authenticity and sustainability" explain the $7.96 \%$ of total variance and include items describing the consumers' desire to be in touch with the locals and their culture, to contribute to their economic health and to respect the environment. Hence, this factor includes items related to what prior studies called sharing economy ethos (Tussyadiah, 2016). The factor confirms the idea that SE is viewed as 
being environmentally friendly (Hamari et al., 2016), and able to allow tourists to live touristic experiences that are authentic (Guttentag, 2015; Kim, 2015) and rich in terms of social interaction (Botsman and Rogers, 2010; Lawson et al., 2016).

"Novelty" summarises $6.91 \%$ of total variance and includes items describing the consumers' wishes to experience something new, unique, unpredictable and exciting that can be told to friends and relatives.

According to prior studies (Guttentag et al., 2018; Tussyadiah, 2016; Tussyadiah and Zach, 2017), "home benefits" (6.39\% of total variance) includes items explaining the decision to use Airbnb for the possibility to reserve an accommodation that allows travellers to have large spaces at their disposal and to access the household facilities.

Finally, "convenience" ( $5.75 \%$ of total variance) is related to the economic and location benefits that can be obtained using Airbnb (e.g. Guttentag et al., 2018; Lamb, 2011; Möhlmann, 2015; Nowak, 2015; Tussyadiah and Zach, 2017).

The scores of the four principal components were entered into a cluster analysis. According to Hair et al. (2014), a hierarchical cluster (Ward method - Manhattan distances) was performed and three groups emerged. Then, a non-hierarchical method (k-means) was applied to factor scores defining the three different groups. The interpretation of each cluster was done analysing the factors scores related to each cluster. Further, in order to better understand the characteristics of each cluster, we calculated and analysed the means value of each item for each cluster (Table 5).

The "Enthusiastic Airbnb lovers" $(\mathrm{N}=78)$ use Airbnb to seek novelty (i.e. something new, unique, different and unpredictable) and the possibility to live an experience that is authentic, rich in term of feelings and emotions (to have an enjoyable, stimulating, fun, interesting and pleasant experience) and to support the local environment and economy. For example, respondents belonging to this cluster scored particularly high (or higher than counterparts) on the following motivations: "To live and enjoyable experience" ( $M=4.19)$, "To live and interesting experience $(M=4.14)$, "To have a nice and pleasant experience $(\mathrm{M}=4.13)$, "To do something new and different" $(\mathrm{M}=4.04)$, "To interact with host, locals $(\mathrm{M}=3.28)$, "To receive useful local info/tips from my host" $(\mathrm{M}=3.37)$, "I wanted the money I spend to go to locals" $(M=3.18)$, "Staying with Airbnb is environmentally friendly" $(M=3.05)$. Despite this, individuals belonging to this cluster show high interest also in functional motivations (e.g. "For its comparatively low cost": $M=4.32$ - "For the convenient location": $M=3.83$ ).

When compared to other clusters, the "Pragmatic Airbnb users" $(\mathrm{N}=8 \mathrm{o})$ use Airbnb mainly for gaining functional benefits. In fact, individuals in this cluster score relatively high in the following motivations: "For its comparatively low cost" $(\mathrm{M}=4.08)$, "For the access to household amenities" $(\mathrm{M}=3.20)$, "For the large amount of space $(\mathrm{M}=3.04)$. On the contrary, they are not interested in the novelty, experiential and sharing economy ethos offered by Airbnb. In fact, they score very low with items such as: "To do something new and different" $(M=1.85)$, "To have a fun experience" $(M=1.85)$, "I thought the experience would be exciting and unique" (M=1.69), "I wanted the money I spent to go to locals" ( $M=2.14)$, "To interact with host, locals" $(M=2.25)$, "To receive useful local info/tips from my host" (M=2.21), "To have an authentic local experience" (M=2.03).

Finally, the "Pragmatic authenticity seekers" $(\mathrm{N}=83)$ are mainly motivated by the comparatively low cost of Airbnb $(\mathrm{M}=4.41)$ and for the home benefits it allows to gain ("For the access to household 
amenities": $M=3.82$, "For the large amount of space": $M=3.47$ "). Further, they are interested in emotional aspects of an Airbnb experience (e.g. "To live an enjoyable experience": M=4.07, "To live an interesting experience": $\mathrm{M=3.92}$ ), but they are not using it for novelty (e.g. "I thought the experience would be exciting and unique": $M=1.92$ ). Finally, they are interested in using Airbnb as a way to experience authentic experience ("To have an authentic local experience": $M=3.78$; "To interact with host, locals": $M=3.34$ ). However, when compared to the Full enthusiastic experiential travellers, Pragmatic authenticity seekers are less motivated by seeking sustainability ("I wanted the money I spent to go to locals": M=3.06; "Staying with Airbnb is environmentally friendly": M=2.59).

Table 5. Results of the Cluster Analysis

\begin{tabular}{|c|c|c|c|c|}
\hline & $\begin{array}{l}\text { Cluster } 1^{\mathrm{a}} \\
(\mathrm{N}=78)\end{array}$ & $\begin{array}{l}\text { Cluster } 2^{b} \\
(\mathrm{~N}=80)\end{array}$ & $\begin{array}{l}\text { Cluster } 3^{\mathrm{c}} \\
(\mathrm{N}=83)\end{array}$ & $\begin{array}{l}\text { Total } \\
(\mathrm{N}=241)\end{array}$ \\
\hline F1: Emotional-based pathos & 0.43091 & -1.00559 & 0.5643 & \\
\hline F2: Authenticity \& sustainability & -0.0185 & -0.46347 & 0.4641 & \\
\hline F3: Novelty & 1.000958 & -0.19769 & -0.75822 & \\
\hline F4: Home benefits & 0.03082 & -0.07179 & 0.04023 & \\
\hline Simple curiosity & 2.73 & 1.84 & 1.77 & 2.1 \\
\hline To interact with host and locals & 3.28 & 2.25 & $3 \cdot 34$ & 2.96 \\
\hline $\begin{array}{l}\text { To receive useful local info/tips from my } \\
\text { host }\end{array}$ & $3 \cdot 37$ & 2.21 & $3 \cdot 58$ & 3.06 \\
\hline For the large amount of space & 3.68 & 3.04 & 3.47 & 3.39 \\
\hline For the access to household amenities & 3.69 & 3.2 & 3.82 & 3.57 \\
\hline For the homely feel & 3.32 & 2.36 & 3.16 & 2.95 \\
\hline $\begin{array}{l}\text { I thought the experience would be } \\
\text { exciting and unique }\end{array}$ & $3 \cdot 55$ & 1.69 & 1.92 & 2.37 \\
\hline To do something new and different & 4.04 & 1.85 & 2.17 & 2.67 \\
\hline $\begin{array}{l}\text { To have experience I could tell } \\
\text { friends/family about }\end{array}$ & 3.4 & 1.5 & 2.02 & 2.29 \\
\hline $\begin{array}{l}\text { I thought the experience would be } \\
\text { unpredictable }\end{array}$ & $3 \cdot 31$ & 1.46 & 1.65 & 2.12 \\
\hline $\begin{array}{l}\text { I wanted the money I spent to go to } \\
\text { locals }\end{array}$ & 3.18 & 2.14 & 3.06 & 2.79 \\
\hline $\begin{array}{l}\text { Staying with Airbnb is environmentally } \\
\text { friendly }\end{array}$ & 3.05 & 1.66 & 2.59 & 2.43 \\
\hline I prefer the philosophy of Airbnb & 3.5 & 1.84 & 3.02 & 2.78 \\
\hline To have an authentic local experience & 3.71 & 2.03 & 3.78 & 3.17 \\
\hline To stay in a non-touristic neighbourhood & $3 \cdot 33$ & 2.23 & 3.33 & 2.96 \\
\hline To live an enjoyable experience & 4.19 & 2.33 & 4.07 & 3.53 \\
\hline To live a stimulating experience & 4.00 & 1.76 & 3.42 & 3.06 \\
\hline To live a fun experience & 4.00 & 1.85 & 3.46 & 3.1 \\
\hline To live an interesting experience & 4.14 & 1.96 & 3.92 & $3 \cdot 34$ \\
\hline To live a nice and pleasant experience & 4.13 & 1.99 & 3.87 & 3.33 \\
\hline For its comparatively low cost & $4 \cdot 32$ & 4.08 & $4 \cdot 41$ & 4.27 \\
\hline For the convenient location & 3.83 & 3.24 & 2.92 & $3 \cdot 32$ \\
\hline
\end{tabular}


Further, a series of chi-square tests were run to investigate whether significant differences among the cluster exist based on socio-demographic characteristics of respondents, namely: age, gender, marital status, level of education, employment status and annual income (Table. 6).

Table 6. Chi-square tests

\begin{tabular}{|c|c|c|c|c|c|}
\hline & Cluster $1^{a}$ & ${\text { Cluster } 2^{b}}^{b}$ & Cluster $3^{c}$ & Chi square & Sig. \\
\hline Gender & & & & 4.246 & 0.120 \\
\hline Male & $37.7 \%$ & $41.3 \%$ & $26.5 \%$ & & \\
\hline Female & $62.3 \%$ & $58.7 \%$ & $73.5 \%$ & & \\
\hline Age & & & & 17.052 & 0.073 \\
\hline $16-20$ & $1.3 \%$ & $2.5 \%$ & $3.6 \%$ & & \\
\hline $21-30$ & $31.2 \%$ & $21.3 \%$ & $43.4 \%$ & & \\
\hline $31-40$ & $37 \cdot 7 \%$ & $42.5 \%$ & $27.7 \%$ & & \\
\hline $41-50$ & $22.0 \%$ & $28.8 \%$ & $15.7 \%$ & & \\
\hline $51-60$ & $7.8 \%$ & $2.5 \%$ & $7.2 \%$ & & \\
\hline$\geq 61$ & $0.0 \%$ & $2.4 \%$ & $2.4 \%$ & & \\
\hline Marital status & & & & 18.509 & 0.018 \\
\hline Single & $20.8 \%$ & $20.0 \%$ & $25.3 \%$ & & \\
\hline Married/cohabiting & $50.6 \%$ & $62.5 \%$ & $37 \cdot 3 \%$ & & \\
\hline Divorced & $2.6 \%$ & $0.0 \%$ & $0.0 \%$ & & \\
\hline Engaged & $26.0 \%$ & $17.5 \%$ & $34.9 \%$ & & \\
\hline Widow & $0.0 \%$ & $0.0 \%$ & $2.5 \%$ & & \\
\hline Education & & & & 17.148 & 0.009 \\
\hline Primary school & $0.0 \%$ & $0.0 \%$ & $0.0 \%$ & & \\
\hline Secondary school & $0.0 \%$ & $0.0 \%$ & $0.0 \%$ & & \\
\hline High school & $30.8 \%$ & $15.0 \%$ & $30.1 \%$ & & \\
\hline University Degree & $46.2 \%$ & $43.8 \%$ & $51.8 \%$ & & \\
\hline Master & $23.1 \%$ & $40.0 \%$ & $15.7 \%$ & & \\
\hline Other & $0.0 \%$ & $0.3 \%$ & $2.4 \%$ & & \\
\hline Employment & & & & $27 \cdot 780$ & 0.037 \\
\hline Executive & $3.9 \%$ & $5.0 \%$ & $4.8 \%$ & & \\
\hline Employee & $32.5 \%$ & $38.7 \%$ & $33.7 \%$ & & \\
\hline Freelance & $19.5 \%$ & $18.7 \%$ & $15.7 \%$ & & \\
\hline Retired & $0.0 \%$ & $0.0 \%$ & $2.4 \%$ & & \\
\hline Professor & $9.1 \%$ & $11.3 \%$ & $3.6 \%$ & & \\
\hline Student & $14.3 \%$ & $15.0 \%$ & $30.1 \%$ & & \\
\hline Unemployed & $11.7 \%$ & $2.5 \%$ & $1.3 \%$ & & \\
\hline Other & $9.1 \%$ & $8.8 \%$ & $8.4 \%$ & & \\
\hline \multicolumn{2}{|c|}{ Monthly Household income } & & & 10.512 & 0.571 \\
\hline$<15,000$ & $9.2 \%$ & $10.0 \%$ & $13 \cdot 3 \%$ & & \\
\hline $15,000-25,000$ & $27.6 \%$ & $26.3 \%$ & $18.1 \%$ & & \\
\hline $25,000-35,000$ & $25.0 \%$ & $17 \cdot 5 \%$ & $19 \cdot 3 \%$ & & \\
\hline $35,000-50,000$ & $15.8 \%$ & $18.8 \%$ & $16.9 \%$ & & \\
\hline$>50,000$ & $10.5 \%$ & $12.5 \%$ & $9.6 \%$ & & \\
\hline I don't Know & $9.2 \%$ & $7 \cdot 5 \%$ & $18.1 \%$ & & \\
\hline No Answer & $2.6 \%$ & $7.5 \%$ & $4.8 \%$ & & \\
\hline
\end{tabular}


Results show that significant differences exist based on marital status $\left(\mathrm{X}_{2}=18.509, \mathrm{p}=0.018\right)$, level of education $\left(\mathrm{X}_{2}=17.148, \mathrm{p}=0.009\right)$ and employment $\left(\mathrm{X}_{2}=27.780, \mathrm{p}=0.037\right)$. On the contrary, no significant differences exist based on gender $\left(\mathrm{X}_{2}=4.246, \mathrm{p}=0.120\right)$, age $\left(\mathrm{X}_{2}=17.052, \mathrm{p}=0.073\right)$ and annual household income $\left(\mathrm{X}_{2}=10.512, \mathrm{p}=0.571\right)$ (Table 4$)$. This occurs despite the fact that one could assume that male, youth and individuals with a lower income should be more prone to use Airbnb. In fact, males are viewed to be usually more risk-taking and sensation-seeking when compared to females (e.g. Pizam et al., 2004), younger people are considered to be more engaged in online behaviours when compared to older individuals (e.g. Yoo and Gretzel, 2011), and consumers with lower household financial status to be more sensitive to price and convenience (e.g. Dellaert and Lindberg, 2003; Wakefield and Inman, 2003).

\section{Conclusion}

Our study was carried out by applying an exploratory mixed method approach with the aim of deepening the scientific debate about motivations driving Italian consumers to use Airbnb to reserve an accommodation for their stay when travelling. Findings of the qualitative study largely confirmed motivations as identified by existing literature (e.g. Guttentag et al., 2018), meanwhile suggesting that further emotional-based motivations should be considered (i.e. living a pleasant, stimulating, fun, interesting and enjoyable experience) when analysing aspects driving consumers to use Airbnb. Hence, applying a factor-cluster analysis our study found four underlying dimensions of motivations, namely: "Emotional-based pathos", "Authenticity and sustainability", "Novelty" and "Home benefits".

Overall, findings reveal that Italians using Airbnb are mainly motivated by functional factors such as: economic benefits, convenient location and home benefits (i.e. availability of household amenities and a large amount of space). The second main group of motivations is represented by more emotional-based experiential drivers such as living an enjoyable, interesting, pleasant and authentic experience. As discussed in prior studies (e.g. Barnes and Mattsson, 2016), environmental-based motivations were found to be the least important. The lower pro-environmental-based motivations of Italians could be explained by referring to the higher level of individualism and materialism that seem to characterise their culture (Hofstede, 2017). The fact that our findings highlight that one of the main motivations to use Airbnb (regardless the considered cluster) is the possibility to save money, confirms and corroborates previous studies' results (Nowak et al., 2015). Further, findings highlight authenticity and sustainability being important motivations to use Airbnb, in particular for supporting Guttentag (2015)'s and Lamb (2011)'s findings.

Further, our study showed that Italians are not homogeneous in terms of motivations to use Airbnb. Specifically, three clusters were identified (Enthusiastic Airbnb lovers, Pragmatic Airbnb users, and Pragmatic authenticity seekers) with significant differences according to marital status, level of education and employment status. On the contrary, the clusters did not differ from others based on age, gender and annual income. This confirms previous studies (e.g. Guttentag et al., 2018) where no significant differences were found according to gender and household income. At the same time, our findings show that clusters differ significantly based on the level of education but not in terms of age, thus contradicting prior studies (i.e. Guttentag et al., 2018) where age and level of education were found to be respectively able and not able to significantly differentiate clusters. Hence, our findings provide contradictory evidence when compared to studies carried out in other countries, thus suggesting that cultural differences still exist in the motivations that drive consumers to use Airbnb, needing to be further investigated through cross-cultural comparisons. 
Our findings also provide useful information for Airbnb managers and for traditional and nontraditional accommodation providers. First, convenience and cost savings resulted the main motivations to use Airbnb. In this vein, Airbnb managers should stress this aspect more in their communication strategies, linking the possibility to save money with the emotional and authenticbased experiences. When aiming to promote Airbnb as a way to live an authentic experience, Airbnb managers should stress brand (e.g. genuineness), existential (e.g. possibility to be in contact with local people, to understand the local culture) and intrapersonal (e.g. to experience something that better represents and nurtures the real self) dimensions of authenticity; in fact, recent studies found these dimensions particularly effective and significant in shaping brand love and loyalty towards the Airbnb platform (i.e. Mody and Hanks, 2019). Further, Airbnb managers should recognise nuances in the motivations driving Italians to use Airbnb based on their sociodemographic characteristics, so that they can run marketing and promotion operations that better reflect the characteristics of their target consumers. Thus, for example, Airbnb managers should stress the comparatively low cost, the home benefits and the emotional aspect of the Airbnb experience when targeting consumers with a higher level of education (i.e. university degree), that were found to mostly belong to the cluster of "pragmatic authenticity seekers". Furthermore, Airbnb hosts could differentiate their communication and product strategies in order to attract certain type of travellers instead of others. For example, to attract Pragmatic Airbnb users they should highlight cost savings, while to attract Pragmatic authenticity seekers they should highlight their accommodations' amenities and simultaneously the enjoyable experience travellers could live during their stay.

Meanwhile, our findings suggest traditional accommodation service providers, particularly the hotel managers, to run their business guaranteeing their guest with more opportunity to experience the local authenticity of the place, to interact with locals and their culture. To achieve this goal, hotel managers, for example, could provide more information about the local culture and authenticity, could use more intensively storytelling about the place (e.g. when providing general information about the place at the reception, when providing information about food and wine served in the restaurant room), organising "resident-based events" in the hotel (e.g. photo exhibitions, cooking class and competitions, meeting with locals acting as storytellers of their places, etc.). Meanwhile, hotels should strongly rely on building, sustaining and positioning their brand authenticity (i.e. genuineness and originality) through effective marketing and promotion operations that can help them to cope with the Airbnb competition. In fact, brand authenticity has been found to be particularly relevant in shaping brand love and loyalty toward hotel services (Mody and Hanks, 2019). When attempting to achieve this aim, hotels should position themselves a sincere and genuine provider of authentic hospitality. For example, hotel official websites could provide, both at a hotel-based and destinationbased level, lifestyle content (e.g. local music, food, arts, folklore, handcraft, insider tips and storytelling from locals, etc.), thus positioning the hotels as a "gateway" to enter and explore the local identity and authenticity.

Although this study helps to fill a gap in the existing body of knowledge and suggests some implication for practitioners, limitations still remain. First, this study was mainly exploratory in nature and utilised a convenience sample obtained from a web-based survey with a snow-ball sampling approach in a single country, thus findings cannot be generalised. Further, it did not consider the moderator effect that other variables (e.g., cultural background, personality, perceived risk and security, etc.) could exert on the way consumers decide to use Airbnb. This aspect would merit future investigation. Particularly, it would be interesting and relevant to replicate the study in different countries that are significantly different based on cultural dimensions as suggested by Hofstede (1993) (individualism, uncertainty avoidance, indulgence, long-term orientation, power distance and 
masculinity) to deeply investigate the extent to which the cultural background of consumers can be considered (or not) as a relevant moderator factor to be used when explaining the motivations to use Airbnb.

\section{References}

Airbnb. (2016). About Us. URL: https://www.airbnb.ca/about/about-us. (Accessed on 23.09.2018)

Airbnb. (2019). Fast Facts URL: https://press.airbnb.com/fast-facts/ (Accessed on 01.09.2019)

Albinsson, P.A., \& Perera, B.Y. (2012). Alternative marketplaces in the 21st century: Building community through sharing events. Journal of Consumer Behaviour, 11(4), 303-315.

Aznar, J. P., Maspera, J. M. S., \& Quer, X. (2019). A Game Theory approach to Airbnb and hotels competition. European Journal of Tourism Research, 21, 119-123.

Bakker, M., \& Twining-Ward, L. (2018). Tourism and the Sharing Economy: Policy and Potential of Sustainable Peer-to-Peer Accommodation. URL: https://elibrary.worldbank.org/ doi/abs/10.1596/30452 (Accessed on 15.06.2019)

Balck, B., \& Cracau, D. (2015). Empirical analysis of customer motives in the share economy: a crosssectoral comparison. Working Paper 2/2015, Otto Von Ricke Universitat Magdeburg, Faculty of Economics and Management.

Barnes, S. J., \& Mattsson, J. (2016). Understanding current and future issues in collaborative consumption: A four-stage Delphi study. Technological Forecasting and Social Change, 104, 200211.

Belk, R. (2014). You are what you can access: Sharing and collaborative consumption online. Journal of Business Research, 7(8), 1595-1600.

Benoita, S. (2017). A triadic framework for collaborative consumption (CC): Motives, activities and resources \& capabilities of actors. Journal of Business Research, 79, 219-227.

Blas, S. S., \& Carvajal-Trujillo, E. (2014). Cruise passengers' experiences in a Mediterranean port of call. The case study of Valencia. Ocean \& coastal management, 102, 307-316.

Botsman, R., \& Rogers, R. (2010). What's mine is yours: The rise of collaborative consumption. New York: HarperCollins Publishers.

Corciolani, M. (2015). Fare e ricevere regali nella sharing economy. Teorie, comunità e pratiche di consumo. Sinergie, 33(98), 287-309.

Creswell, J. W., \& Plano Clarke, V. L. (2017). Designing and conducting mixed methods research (3rd ed.). Thousand Oaks (CA): SAGE.

Crompton, J. L. (1979). Motivations for pleasure vacation. Annals of Tourism Research, 6(4), 408-424.

Decrop, A., Del Chiappa, G., Mallarge, J., \& Zidda, P. (2018). Couchsurfing has made me a better person and the world a better place: the transformative power of collaborative tourism experiences. Journal of Travel \& Tourism Marketing, 35(1), 57-72.

Dellaert, B.G., \& Lindberg, K. (2003). Variations in tourist price sensitivity: a stated preference model to capture the joint impact of differences in systematic utility and response consistency. Leisure Sciences, 25(1), 81-96.

Dolnicar, S. (2018). Peer to Peer Accommodation Networks: An Examination. Oxford: Goodfellow Publishers Ltd.

Dudás, G., Kovalcsik, T., Vida, G., Boros, L., \& Nagy, G. (2019). Price determinants of Airbnb listing prices in Lake Balaton Touristic Region, Hungary. European Journal of Tourism Research, 23 (forthcoming).

Federalberghi (2016). Locazioni brevi e sharing economy. URL: http://intranet.federalberghi.it:8ooo/ pubblicazioni/Pub/Locazioni\%2obrevi\%20e\%2osharing\%2oeconomy/sharing\%2oeconomy\%2o\%2oterza\%2oedizione\%2oweb.pdf (Accessed on 07.09.2017). 
Federalberghi (2017). Turismo e shadow economy. Tutela del consumatore, concorrenza leale e equità fiscale al tempo del turismo 4.o. URL: http://intranet.federalberghi.it:80oo/pubblicazioni/ Pub/Turismo\%2oe\%2oshadow\%2oeconomy/Turismo\%2oe\%2oshadow\%2oeconomy\%2ovolume. pdf (Accessed on 07.09.2017).

Forgas-Coll, S., Palau-Saumell, R., Sánchez-García, J., \& Callarisa-Fiol, L. J. (2012). Urban destination loyalty drivers and cross-national moderator effects: The case of Barcelona. Tourism Management, 33(6), 1309-1320.

Freitag, J. D., \& Haywood, J. (2015). Digging the core of Airbnb's Big Apple data. Hotel News Now. URL: http://www.hotelnewsnow.com. (Accessed on 07.09.2017).

Gretzel, U., Werthner, H., Koo, C., \& Lamsfus, C. (2015). Conceptual foundations for understanding smart tourism ecosystems. Computers in Human Behavior, 50, 558-563.

Guttentag, D. (2015). Airbnb: disruptive innovation and the rise of an informal tourism accommodation sector. Current Issues in Tourism, 18(12), 1192-1217.

Guttentag, D., Smith S., Potwarkal. S, \& Havitz M. (2018). Why Tourists Choose Airbnb: A MotivationBased Segmentation Study. Journal of Travel Research, 57(3), 1-18.

Hair, J.F., Black, W.C., Babin, B.J., \& Anderson R.E. (2014). Multivariate data analysis (7th ed.), Edinburgh Gate: Pearson Education Limited.

Hamari, J., Sjoklint, M., \& Ukkomen, A. (2016). The sharing economy: Why people participate in collaborative consumption. Journal of the Association for Information Science and Technology, 67(9), 2047-2059.

Hardy, A., \& Dolnicar, S. (2018). Types of Network members. In Dolnicar S. (eds.) (2018). Peer to Peer Accommodation Networks: An Examination. Oxford: Goodfellow Publishers Ltd.

Hofstede, G., (2017). Comparison Italy - USA - Canada. URL: https://geert-hofstede.com/italy.html. (Accessed on 12.09.2018).

Hofstede, G., (1993). Cultural Constraints in management theories. The Accademy of Management Executive, 7(19), 81-93.

Hsu, A. Y. C., King, B., Wang, D., \& Buhalis, D. (2016). In-destination tour products and the disrupted tourism industry: progress and prospects. Information Technology E Tourism, 16(4), 413-433.

Kim, J. (2015). Why people participate in the sharing economy: a social exchange perspective. In Y. Yoon \& H. Zo (eds.) (2015). Proceedings of Pacific Asia Conference on Information Systems (PACIS).

Kotler, P. (1980). Principles of marketing. Englewood Cliffs, New Jersey: Prentice-Hall.

Lamb, Z. (2011). Rethinking Authenticity in Tourist Experience: Analyzing the Motivations of Travelers in $P_{2} P$ Hospitality Networks. Master's thesis: University of Chicago

Lawson, S.J., Gleim, M.R., Perren, R., \& Hwang, J. Y. (2016). Freedom from ownership: An exploration of access-based consumption. Journal of Business Research, 69(8), 2615-2623.

Mody, M., \& Hanks, L. (2019). Consumption authenticity in the accommodations industry: the keys to brand love and brand loyalty for hotels and Airbnb. Journal of Travel Research, doi: 10.1177/0047287519826233.

Möhlmann, M. (2015). Collaborative consumption: determinants of satisfaction and the likelihood of using a sharing economy option again. Journal of Consumer Behaviour, 14(3), 193-207.

Nowak, B. (2015). Global Insight: Who Will Airbnb Hurt More-Hotels or OTAs? In Allen T., Rollo, J., Lewis, V., He, L., Chen, A., Wilson, W. N., Costantini, M., Hyde, O., Liu, K., Savino, M., Chaudhry, A. M., Grube B. A., \& Young E., (eds.) (2015). Morgan Stanley Research. Report.

Palgan, Y. V., Zvolska, L., \& Mont, O. (2017). Sustainability framings of accommodation sharing. Environmental Innovation and Societal Transitions, 23, 70-83.

Patton, M. Q. (2002). Qualitative research and evaluation methods. Thousand Oaks: Sage. 
Pizam, A., \& Sussmann, S. (1995). Does nationality affect tourist behavior? Annals of Tourism Research, 22(4), 901-917.

Pizam, A., Jeong, G.H., Reichel, A., Van Boemmel, H., Lusson, J.M., Steynberg, L., State-Costache, O., Volo, S., Kroesbacher, C., Kucerova, J., \& Montmany, N. (2004). The relationship between risktaking, sensation-seeking, and the tourist behavior of young adults: A cross-cultural study. Journal of Travel Research, 42(3), 251-260.

Prothero, A., Dobscha, S., Freund, J., Kilbourne, W.E., Luchs, M.G., \& Ozanne, L. K., (2011). Sustainable Consumption: Opportunities for Consumer Research and Public Policy. Journal of Public Policy \& Marketing, 30(1), 31-38.

Quinby, D. (2014). Share This! Private Accommodation $\mathcal{E}$ the Rise of the New Gen Renter. Phocuswright. URL: http://www.phocuswright.com/Travel-Research/Consumer-Trends/ShareThis-Private-Accommodation-the-Rise-of-the-New-Gen-Renter. (Accessed on 24.09.2018).

Reinhold, S., \& Dolnicar, S. (2017). The sharing economy. In S. Dolnicar (ed.) (2017). Peer-to-peer accommodation networks: Pushing the boundaries. Oxford: Goodfellow Publishers, 15-26.

Seabra, C., Silva, C., Abrantes, J. L., Vicente, M., \& Herstein, R. (2016). The influence of motivations in tourists' involvement. Anatolia: International Journal of Tourism and Hospitality Research, 27(1), 4-15.

Sthapit, E., Del Chiappa, G., Coudounaris, D., \& Bjork, P. (2019). Determinants of the continuance intention of Airbnb users: Consumption values, co-creation, information overload and satisfaction. Forthcoming in Tourism Review.

Suh, E. E., Kagan, S., \& Strumpf, N. (2009). Cultural competence in qualitative interview methods with Asian immigrants. Journal of Transcultural Nursing, 20(2), 194-201.

Teddlie, C., \& Tashakkori, A. (2009). Foundations of mixed methods research: Integrating quantitative and qualitative approaches in the social and behavioral sciences. Thousand Oaks: Sage.

Torres, E. N., Fu, X., \& Lehto, X. (2014). Examining key drivers of customer delight in a hotel experience: A cross-cultural perspective. International Journal of Hospitality Management, 36, 255-262.

Tussyadiah, I. P. (2015). An exploratory study on drivers and deterrents of collaborative consumption in travel. In: I. Tussyadiah, \& A. Inversini (eds.) (2015). Information and Communication Technologies in Tourism 2015. Cham: Springer, 819-832.

Tussyadiah, I. P. (2016). Factors of satisfaction and intention to use peer-to-peer accommodation. International Journal of Hospitality Management, 55, 70-80.

Tussiadiah, I. P., \& Zach, F. (2017). Identifying salient attributes of peer-to-peer accommodation experience. Journal of Travel E Tourism Marketing, 34(6), 636- 652.

Volgger, M., Taplin, R., \& Pforr, C. (2019). The evolution of 'Airbnb-tourism': Demand-side dynamics around international use of peer-to-peer accommodation in Australia. Annals of Tourism Research, 75, 322-337.

Wakefield, K. L., \& Inman, J. J. (2003). Situational price sensitivity: the role of consumption occasion, social context and income. Journal of Retailing, 79(4), 199-212.

Wrenn, B., Stevens, R. E., \& Loudon, D.L. (2007). Marketing research: Text and cases. New York: Haworth Press.

Yoo, K. H., \& Gretzel, U. (2011). Influence of personality on travel-related consumer-generated media creation. Computers in Human Behavior, 27(2), 609-621.

Received: 03/04/2019

Accepted: 18/10/2019

Coordinating editor: Basak Denizci Guillet 


\section{Appendix}

Table 1. Socio Demographic profile of the qualitative interview sample

\begin{tabular}{|c|c|c|c|c|c|c|c|}
\hline Gender & Age & Study & Job & $\begin{array}{l}\text { Booked } \\
\text { Online }\end{array}$ & $\begin{array}{l}\text { Booked } \\
\text { how? }\end{array}$ & SE user & Code \\
\hline $\mathrm{F}$ & 58 & Master's Degree & Professor & Yes & Alone & Yes & SEo1 \\
\hline M & 31 & Master's Degree & Freelance & Yes & Alone & No & SEo2 \\
\hline M & 37 & Master's Degree & Freelance & Yes & Alone & Yes & SEo3 \\
\hline M & 47 & $\mathrm{PhD}$ & Professor & Yes & Alone & Yes & SEo4 \\
\hline $\mathrm{F}$ & 33 & Master's Degree & Employee & Yes & Alone & Yes & SEo5 \\
\hline M & 32 & Master's Degree & Employee & Yes & Alone & Yes & SEo6 \\
\hline M & 36 & Master's Degree & Employee & Yes & Alone & Yes & SEo7 \\
\hline M & 47 & Master's Degree & Freelance & Yes & Alone & No & SEo8 \\
\hline $\mathrm{F}$ & 26 & Master's Degree & Student & Yes & Alone & No & SEog \\
\hline $\mathrm{F}$ & 32 & Master's Degree & Employee & Yes & Alone & No & SE10 \\
\hline M & 41 & Master's Degree & Employee & Yes & Alone & Yes & SE11 \\
\hline M & 61 & High School & Entrepreneur & Yes & Alone & Yes & SE12 \\
\hline $\mathrm{F}$ & 32 & Master's Degree & Freelance & Yes & Alone & Yes & SE13 \\
\hline $\mathrm{F}$ & 58 & Master's Degree & Professor & Yes & Alone & Yes & SE14 \\
\hline $\mathrm{F}$ & 39 & Master's Degree & Freelance & Yes & Alone & Yes & SE15 \\
\hline $\mathrm{F}$ & 33 & Master's Degree & Internship & Yes & Alone & Yes & SE16 \\
\hline $\mathrm{F}$ & 34 & Master's Degree & Employee & Yes & Alone & Yes & SE17 \\
\hline M & 40 & High school & Employee & Yes & Alone & No & SE18 \\
\hline $\mathrm{F}$ & 30 & Master's Degree & Employee & Yes & Alone & Yes & SE19 \\
\hline $\mathrm{F}$ & 33 & Master's Degree & Employee & Yes & Alone & Yes & SE2O \\
\hline M & 34 & Master's Degree & Employee & Yes & Alone & Yes & SE21 \\
\hline M & 35 & $\mathrm{PhD}$ & Freelance & Yes & Alone & Yes & SE22 \\
\hline $\mathrm{F}$ & 38 & Master's Degree & Employee & Yes & Alone & Yes & $\mathrm{SE} 23$ \\
\hline $\mathrm{F}$ & 50 & $\mathrm{PhD}$ & Employee & Yes & Alone & Yes & $\mathrm{SE24}$ \\
\hline $\mathrm{F}$ & 35 & Master's Degree & Freelance & Yes & Alone & Yes & $\mathrm{SE25}$ \\
\hline M & 35 & $\mathrm{PhD}$ & Entrepreneur & Yes & Alone & Yes & SE26 \\
\hline
\end{tabular}

